\title{
EDITORIAL
}

Elis de Almeida Cardoso [htrps://orid.org/0000-0002-8089-8716]

Universidade de São Paulo, São Paulo, SP, Brasil

Maria Inês Batista Campos [htpps://orid.org/0000-0003-0004-9923]

Universidade de São Paulo, São Paulo, SP, Brasil

\section{ESTUDOS LEXICAIS EM FOCO}

\section{Algumas considerações sobre os estudos lexicais}

Certa palavra dorme na sombral de um livro raro./ Como desencantá-la?/ É a senha da vida/ a senha do mundo./Vou procurá-la. Vou procurá-la a vida inteiral no mundo todo. / Se tarda o encontro, se não a encontro,/ não desanimo,/

procuro sempre.

Procuro sempre, e minha procural ficará sendol minha palavra.

Palavra mágica, Carlos Drummond de Andrade

Na descrição e análise linguística de um texto, não só a expressão de valores como também posicionamentos sócio-históricos devem estar no foco do pesquisador. Elementos extralinguísticos como a situação, o contexto, os papéis sociais assumidos revelam não só a intencionalidade discursiva, mas também os valores ideológicos. São os diferentes efeitos de sentido produzidos, revelados pelas escolhas lexicais, que mostram a intenção do autor e seu posicionamento frente ao contexto. 
A expressividade "nasce do ponto de contato da palavra com a realidade concreta e nas condições de uma situação real, contato esse que é realizado pelo enunciado individual" (BAKHTIN, 2003, p.294).

Sendo o léxico o conjunto organizado de signos para a categorização e nomeação da realidade - mesmo tendo um limite impreciso -, é ele o responsável pelas associações de sentidos, pelo resgate de valores, pela ampliação e reorganização dos significados (CARDOSO, 2018). Por isso, o compósito léxico reflete tanto as mudanças dos sistemas sociais, quanto linguísticos em que residem os fatos culturais servidos pelos usos lexicais e os fatos da língua que são definidos pelos acontecimentos culturais.

Biderman afirma que:

o Léxico de qualquer língua constitui um vasto universo de limites imprecisos e indefinidos. Abrange todo o universo conceptual dessa língua. Qualquer sistema léxico é a somatória de toda a experiência acumulada de uma sociedade e do acervo da sua cultura através das idades. Os membros dessa sociedade funcionam como sujeitos-agentes, no processo de perpetuação e reelaboração contínua do Léxico da sua língua (1978, p. 139).

Para Vilela,

o léxico é o subsistema da língua mais dinâmico, porque é o elemento mais diretamente chamado a configurar linguisticamente o que há de novo, e por isso é nele que se refletem mais clara e imediatamente todas as mudanças ou inovações políticas, econômicas, sociais, culturais ou científicas (1994, p. 14).

O léxico é "patrimônio da comunidade linguística" (BIDERMAM, 1978, p. 139), e são os usuários da língua os responsáveis por todas as suas transformações. São eles que criam novas palavras, que mantêm palavras já existentes, ou que alteram a sua significação.

Em se tratando do uso criativo do léxico, a exploração dos significados de forma original faz com que uma palavra possa ter o seu campo semântico ampliado ou ainda modificado. O significado referencial (denotativo, conceptual) pode dar lugar ao significado não-referencial (conotativo, estilístico, emotivo). De acordo com Antunes (2012, p.28): "O léxico corresponde, assim, ao inventário dos itens linguísticos com que expressamos essas categorias e subcategorias cognitivas”. 
Linha D’Água (Online), São Paulo, v. 32, n. 3, p. 1-8, set.-dez. 2019

Se por trás de um lexema é possível distinguir um significado conceptual, onde se percebe uma referência direta à realidade, por outro, é possível encontrar significados conotativos em uma referência a atitudes e/ou sentimentos do enunciador.

Para Coseriu (1958) a motivação geral da mudança linguística é a finalidade expressiva (e comunicativa) dos falantes. As transformações sociais, o surgimento de novos inventos e conceitos fazem com que os neologismos se relacionem não só às transformações da língua, mas sobretudo à evolução do conhecimento. Sem dúvida os neologismos possuem uma estreita relação com o contexto social em que foram criados. De acordo com Guiraud (1978, p.23), "as palavras guardam o reflexo das coisas que designam ou dos ambientes em que são empregadas". Cada estado da língua possui palavras-testemunho ou neologismos correspondentes a novas noções de realidade que surgem no seio da coletividade, em um dado momento histórico. Por essa razão, afirma-se que os neologismos revelam as ideologias e as visões de mundo dos falantes de uma língua.

Neste número, Linha d'Água convida todos os interessados a mergulharem nas riquezas do universo lexical e enxergarem suas relações com o discurso, seja ele literário, publicitário ou jornalístico, com a neologia, com a etimologia, com o ensino. Os nove artigos deste número refletem resultados de pesquisas e apresentam grande contribuição para os estudos lexicais.

\section{Os estudos lexicais em Linha d'Água}

Os artigos que compõem este número da revista Linha d’Água enfocam o léxico em suas mais diferentes interfaces: neologia, semântica, estilística, etimologia, ensino. Treze pesquisadores de instituições estrangeiras (Portugal, Espanha, Angola) e brasileiras (São Paulo, Rio de Janeiro, Mato Grosso do Sul, Ceará e Pará) apresentam os resultados de suas pesquisas, levando em consideração a importância dos estudos lexicais aplicados em diferentes gêneros discursivos e também no ensino. Pluralidades geográficas estabelecem um diálogo convergente neste número que traz à tona a importância da palavra.

O recurso principal de que as línguas se valem para ampliar o léxico é a formação de palavras a partir de palavras e/ou morfemas preexistentes. Os processos de formação de palavras, segundo Basílio (1987, p.65), podem desempenhar duas 
Linha D’Água (Online), São Paulo, v. 32, n. 3, p. 1-8, set.-dez. 2019

funções, a semântica e a sintática, às quais se pode acrescentar, conforme o caso, uma função discursiva.

Formar palavras para dar nome a seres ou objetos, a fatos culturais novos e a fenômenos da natureza é, para Sandmann (1992), fato bastante comum da atividade linguística. Nesses casos, seria possível falar em uma função semântica dos processos de formação de palavras. Já quando um processo opera uma mudança de classe de palavra (de verbo para substantivo, ou adjetivo, por exemplo), faz-se presente a função sintática. Vale ressaltar que uma não exclui a outra. Entretanto, não se pode negar que muitas palavras formadas na língua atendem a necessidades expressivas. Entra em cena, então, a função discursiva que, para o autor, tem "a função de expressar aspectos subjetivos do emissor em relação ao conteúdo do que é comunicado e a função de adequação discursiva" (1992, p.23).

Os neologismos são simultaneamente uma manifestação da evolução da língua e da evolução do conhecimento que acontecem com um ritmo extremamente rápido. Maria Teresa Rijo da Fonseca Lino, professora da Universidade Nova de Lisboa (Portugal), apresenta no artigo "Neologia e neonímia em língua portuguesa" algumas reflexões sobre os critérios de identificação e delimitação tanto de neologismos de língua corrente, quanto de neônimos (neologismos científicos e técnicos). O conceito de "sentimento neológico", diz a pesquisadora, revela-se, hoje, fundamental como critério de identificação de neologismos e de neônimos. Em seu artigo, ela destaca a importância das metodologias da Linguística de Corpus e dos hipertextos no tratamento semiautomático dos corpora para a extração de neologismos, apontando a importância da criação de Observatórios de Neologia que permitem a observação e a comparação dos fenômenos de neologia da Língua Portuguesa em vários países.

Apresentando uma reflexão sobre a neologia do português em Angola, José Cambuta, professor do Instituto Superior Politécnico Católico do Huambo (Angola), tece considerações sobre o ensino de língua portuguesa em um país plurilíngue e multicultural no texto intitulado "A 'didactização' da neologia do Português". Ao pesquisar o comportamento linguístico do português no contato com a língua umbundu, o autor verifica de que forma é possível levar ao contexto escolar o ensino da neologia como componente complementar ao ensino da gramática. Com a "didactização" da neologia, Cambuta mostra que os alunos adquirem consciência linguística quando "evidenciam capacidades metalinguísticas, uma vez que assumem 
Linha D'Água (Online), São Paulo, v. 32, n. 3, p. 1-8, set.-dez. 2019

já uma perspectiva distanciada e não holística do conhecimento da língua" (DUARTE, 2010, p. 12). É a consciência linguística que conduz à competência linguística que representa para o aluno o estágio mais elevado na manipulação, reflexão e juízo crítico e produção de enunciados mais especializados, diz o pesquisador.

Também tendo por foco o ensino do léxico, Beatriz Daruj Gil, pesquisadora da Universidade de São Paulo, mostra, com base nos pressupostos de Richards (1976) sobre o que é conhecer uma palavra, que o estudo do léxico envolve um saber pluridimensional do qual fazem parte aspectos gramaticais, semânticos e discursivos da unidade lexical. Cabe ao professor explorar aspectos semânticos do léxico que contribuam para que o aluno saiba empregá-lo, principalmente por meio de redes associativas, da polissemia e da parassinonímia. A autora apresenta em seu artigo "Exploração de redes associativas no ensino do léxico" um conjunto de atividades sobre léxico proposto por professores da educação básica, participantes de curso de extensão na Universidade de São Paulo.

Refletindo sobre o aprendizado pelos "neolfalantes" de uma língua não materna, Valéria Gil Condé, professora da Universidade de São Paulo, Ana Alicia Manso Flores, doutoranda da Universidad de Extremadura (Espanha) e Priscila Vasconcelos Silva, mestranda na Universidade de São Paulo, abordam políticas e enfoques pedagógicos focados na inserção linguística do sujeito, visando a seu êxito escolar e social. Partindo da diversidade linguística nas aulas, com enfoque no léxico, as pesquisadoras discutem um caso prático ocorrido na escola de ensino secundário da localidade de Burela (Galicia, Espanha), verificando as possibilidades de incorporar essa concepção no âmbito do ensino brasileiro, para que a dicotomia norma culta versus oralidade não seja sinônimo de estigmatização social.

A renovação lexical na linguagem midiática é abordada por André Crim Valente, da Universidade do Estado do Rio de Janeiro. Buscando a integração entre léxico e discurso, o pesquisador da UERJ aponta, no artigo "Aspectos semântico-discursivos da renovação lexical em época de Lava Jato e governo Bolsonaro" que o atual momento político tem possibilitado a criação de neologismos que mostram que até uma área árida como a política pode ser fértil para a criatividade lexical. Apresentando os diferentes tipos de criações lexicais, o autor apresenta exemplos de neologismos formais e semânticos que se relacionam à operação Lava Jato e ao governo Bolsonaro. 
Linha D’Água (Online), São Paulo, v. 32, n. 3, p. 1-8, set.-dez. 2019

Alessandra Ferreira Ignez e Eliana Maria Azevedo Roda Pessoa Ferreira, do Instituto Federal de São Paulo apresem exemplos de substituições lexicais criativas no artigo "Troca vocabular: humor e expressividade nas propagandas da Hortifruti”, que aborda a escolha lexical no discurso publicitário. Os textos multimodais analisados priorizam os aspectos lúdicos, explorando o jogo de ideias e palavras. Apelam para a memória e para o repertório do leitor/ consumidor, que compreende as paródias e as brincadeiras intertextuais das campanhas publicitárias da rede Hortifruti. As autoras analisam o corpus selecionado à luz da Estilística Léxica, que se ocupa da expressividade das palavras.

O discurso literário é objeto de análise de Vicente de Paula da Silva Martins e Márton Tamás Gémes, pesquisadores vinculados à Universidade Estadual Vale do Acaraú (Ceará). O artigo intitulado "Os idioculturemas em Capitães da Areia (1937), de Jorge Amado" objetiva analisar as escolhas lexicais do escritor, considerando que a linguagem utilizada por Jorge Amado é um reflexo da interação entre sociedade, língua, literatura e cultura. Partindo do pressuposto de que os chamados culturemas - geralmente expressos em unidades do léxico ou lexias de diversos níveis (complexas, compostas e simples) - são parte do patrimônio línguo-cultural, verifica-se no artigo de que forma essas palavras e expressões escolhidas por Jorge Amado são importantes para determinar os traços e a construção sociocultural do universo descrito no romance.

Sandra Mina Takakura traz para a revista a obra poética de Arnaldo Antunes. Em seu texto "A tensão entre a luz e a sombra: um estudo das mesclagens conceituais em Luzescrita, as obras intermidiáticas de Arnaldo Antunes", a pesquisadora da Universidade do Estado do Pará estuda as metáforas utilizadas pelo poeta em uma pequena seleção de obras da exposição intitulada Luzescrita (2013). Por meio das metáforas complexas e plurissignificativas que permitem pensar em mesclagens de conceitos, são explorados os efeitos de genericidade, propostos por Adam e Heidmann (2004), que possibilitam identificar os traços poéticos e artísticos nas obras. Considerando a literatura e a arte como mídias distintas, são apontados no texto tanto o hibridismo das produções por meio da intermidialidade de Rajewsky (2012) e Clüver (2006; 2008), quanto a noção de mesclagem conceitual de Fauconnier e Turner (2002).

Por fim, a etimologia é foco do artigo de Bruno Maroneze, professor da Universidade Federal da Grande Dourados (Mato Grosso do Sul). O pesquisador, 
Linha D’Água (Online), São Paulo, v. 32, n. 3, p. 1-8, set.-dez. 2019

em "A história da pétala: etimologia de um termo científico", descreve a diacronia da palavra pétala, termo da Botânica que apresenta duas formas concorrentes em português: pétala (feminino) e pétalo (masculino). A partir de conceitos teórico-metodológicos da Etimologia, o artigo apresenta quatro hipóteses para a existência de ambas as formas em português: o feminino originado do neutro plural latino; a influência do gênero feminino de folha; a influência do adjetivo apétalo na forma feminina; e a influência no português de outras línguas em que também ocorre a oscilação de gênero.

A publicação deste número recebe o auxílio do Programa de Apoio às $\mathrm{Pu}$ blicações Científicas Periódicas da Universidade de São Paulo/SIBi, a quem agradecemos por permitir a indexação de Linha d'Água na Web of Science, base de dados de citações científicas do Institute for Scientific Information, mantida pela Clarivate Analytics, nas áreas de Ciências Sociais, Artes e Humanidades.

A revista conta com pareceristas do Conselho Editorial e ad hoc e com um corpo de revisores de língua portuguesa de excelência, o que garante sua alta qualidade. Conta também com o trabalho de revisão de tradução, realizado pela professora Roseli Serra, da Universidade Católica de Pernambuco.

Com este número da revista, o Conselho Editorial busca a internacionalização do periódico, uma vez que recebemos artigos de autores de universidades estrangeiras, procurando responder às exigências da Universidade de São Paulo e das agências internacionais. Linha d'Água torna-se, assim, um espaço aberto a publicações ligadas aos estudos de língua portuguesa, aos estudos linguísticodiscursivos e sua relação com o ensino, mantendo um diálogo constante com as pesquisas desenvolvidas no Brasil e no exterior.

\section{Referências}

ADAM, J. M.; HEIDMANN, U. Des genres à la généricité: l'exemple des contes (Perrault et les Grimm). In: Langages, 38 année, n. 153, p. 62-72, 2004.

ANTUNES, I. Território das palavras: estudo do léxico em sala de aula. São Paulo: Parábola, 2012.

BAKHTIN, M. Estética da criação verbal. São Paulo: Martins Fontes, 2003. 
Linha D’Água (Online), São Paulo, v. 32, n. 3, p. 1-8, set.-dez. 2019

BASÍLIO, M. Teoria lexical. São Paulo: Ática, 1987.

BIDERMAN, M.T.C. Teoria linguistica: linguistica quantitativa e computacional. Rio de Janeiro: Livros Técnicos e Científicos, 1978.

CARDOSO, E.A. O léxico no discurso literário. São Paulo: EDUSP, 2018.

CLÜVER, C..Intertextos / Interartes / Inter mídia. Aletria 14, p.9-39, jul.- dez., 2006.

CLÜVER, C. Intermidialidade. Pós: Revista do Programa de Pós-Graduação em Artes da Escola de Belas Artes da UFMG, v. 1, n, n2, p. 8-23, nov. 2008.

COSERIU, E. Sincronía, Diacronía y História. El problema del cambio linguistico. Montevideo: Universidad de La Repúlica, 1958.

GUIRAUD, P. A estilistica. São Paulo: Mestre Jou, 1978.

DUARTE, I. Sobre o conceito de consciência linguística. In: FREITAS, M. J. - GONÇALVES, A. DUARTE, I. (Org.) Avaliação da consciência linguística. Aspectos fonológicos e sintácticos do Português. Lisboa: Edições Colibri, 2010.

FAUCONNIER, G.; TURNER, M. The way we think: conceptual blending and the mind's hidden complexities. New York: Best Books, 2002.

RAJEWSKY, I. O. intermidialidade, intertextualidade e "remediação". In: DINIZ Thaïs Flores Nogueira (Org.). Intermidialidade e Estudos interartes. Belo Horizonte: UFMG, p. 15-45, 2012.

RICHARDS, J. The role of vocabulary teaching. TESOL Quartely, vol 10, n. 1, p. Mar 1976.

SANDMANN, J.A. Morfologia lexical. São Paulo: Contexto, 1992.

VILELA, M. Estudos de lexicologia do português. Coimbra: Almedina, 1994.

São Paulo, dezembro de 2019. 